\title{
E-smoking among students of medicine - frequency, pattern and motivations
}

The authors declare no financial disclosure

\begin{abstract}
Introduction: E-smoking has become a public health problem. The objectives of this study were to assess the prevalence of e-cigarette and tobacco cigarette use; to compare the patterns of smoking; to assess the attitudes and motivations for e-cigarette use. Material and methods: All 1,700 students from Faculty of Medicine (Medical University of Silesia) were invited to questionnaire based cross-sectional study about the frequency and attitudes towards the use of traditional and electronic cigarettes.

Results: The data were obtained from 1,318 medical students (response 77.5\%) aged $22.1 \pm 2.2$ years. Traditional tobacco smoked $18.1 \%$, e-cigarettes $1.3 \%$ and $2.2 \%$ were dual smokers. The overall frequency of e-smokers was $4.9 \%$ among men and $2.8 \%$ among women $(p=0.05)$. Compared to tobacco users in e-smokers duration of smoking was shorter $(p<0.001)$, the intensity of smoking was larger $(p=0.01)$, the number of e-cigarettes smoked daily was higher $(p<0.001)$. Dual smokers more frequently used tobacco cigarettes than e-cigarettes $(p=0.01)$ but smoked more e-cigarettes daily $(p=0.003)$. The choice of e-liquid depended on the flavour (50.0\%), nicotine concentration $(21.7 \%)$ and price $(7.6 \%)$. No-nicotine e-cigarettes were used by $6.5 \%$ smokers. Dual smokers more frequently chose e-liquids with high nicotine concentration $(p=0.01)$. Motivations leading to e-smoking were: quitting tobacco $(58.7 \%)$, less harmful impact on health $(43.5 \%)$ and the price $(34.8 \%)$. E-smoking as safe for health was perceived by $6.0 \%$ of respondents ( $35.5 \%$ in e-smokers vs. $4.9 \%$ in non e-smokers; $p<0.001$ ).

Conclusion: Among students of medicine, e-smoking is apparently less popular than smoking tobacco cigarettes. Respondents considered e-cigarettes to be harmful and addictive.
\end{abstract}

Key words: electronic cigarettes, smoking, nicotine, tobacco products, medical students

Adv Respir Med 2017; 85: 8-14

\section{Introduction}

E-smoking (smoking of electronic cigarettes) is advertised in the media as a healthy alternative to smoking tobacco cigarettes [1]. In an e-cigarette device, the fluid (e-liquid) contains glycerine and/or propylene glycol and nicotine in different concentrations as well as flavouring substances. These are heated and generate an aerosol that is then inhaled by the user [1]. The prevalence of e-smoking differs across populations in Europe [2]. Because of the short length of time that e-cigarettes have been available, approximately 10 years, the long-term health effects of e-smoking are not yet known [1]. The emerging evidence indicates that the increasing popularity of e-smoking creates a potentially new challenge for public health [3, 4]. The World Health Organization (WHO) recommends a precautionary measure of limiting the sale of e-cigarettes to minors, as well as advertising in media [4].

The objectives of this study were to (1) assess the prevalence of e-cigarette and tobacco cigarette use among Polish medical university students; (2) compare the patterns of tobacco smoking and esmoking in this group; and (3) assess the attitudes and motivations for e-cigarette use.

Address for correspondence: Grzegorz M. Brożek, Department of Epidemiology, School of Medicine, Medical University of Silesia in Katowice, e-mail: gbrozek@sum.edu.pl DOI: 10.5603/ARM.2017.0003

Received: 4.10.2016

Copyright (C) 2017 PTChP

ISSN 2451-4934 


\section{Material and methods}

A survey was conducted between January and April 2016. All 1,700 students in the Faculty of Medicine at the Medical University of Silesia in Katowice (Poland) attending school in this time period were eligible. The questionnaire included 35 questions related to the frequency and attitudes towards the use of traditional and electronic cigarettes. The questions also addressed safety concerns (health impact), smoking in public places, views regarding addiction, and the presence of respiratory symptoms as well as personal motivations behind e-smoking and smoking pattern. The questionnaire was validated in a pilot study where 54 students completed the survey twice, two days apart. Depending on the question and subscale, Cronbach's alpha ranged between 0.72-0.92; the kappa coefficient ranged from 0.62 to 0.95 . Participation in the study was voluntary and anonymous. The study protocol was reviewed and approved by the Ethical Review Board at the Medical University of Silesia, Poland.

Subjects were classified into one of four groups based on their smoking status: e-cigarette smokers only, tobacco cigarette smokers only, dual smokers (students who use both e-cigarettes and tobacco cigarettes), and non-smokers. The data was analysed with Statistica 10 Software (StatSoft, USA). Normality of distributions of continuous variables was assessed by the Shapiro-Wilk test. Statistical significance of differences between continuous variables was analysed by the independent samples t-test or the Mann-Whitney U test if the assumptions for the t-test were not met. Distribution of categorical variables was shown by frequencies and proportions along with 95\% confidence intervals. Statistical testing to compare between categorical variables was completed using the independent samples chi-square test. Statistical inference was based on the criterion $\mathrm{p}<0.05$.

\section{Results}

Completed questionnaires were obtained from 1,318 medical students (response rate: $77.5 \%)$. The average age of the respondents was $22.1 \pm 2.2$ years (range 18-35) with no differences between males and females $(p=0.3)$. The group included more women than men $(65.6 \%$ vs. $34.4 \%$ ), which reflects the sex distribution of the students of medicine at the University.

\section{Frequency and distribution of smoking and e-smoking}

The majority of the group (78.4\%) were nonsmokers. Traditional tobacco smoking was declared by 239 (18.1\%) respondents while e-cigarette were used by $46(3.5 \%)$ of the participants. The distribution of smoking differed $(p=0.02)$ between men and women, with a higher frequency of smoking of all types of cigarettes in men (Table 1). The overall frequency of e-smokers (exclusive or dual) was $4.9 \%$ among men and $2.8 \%$ among women and the difference was on the border of statistical significance $(p=0.05)$.

\section{Patterns of cigarette and e-cigarette use}

Duration of smoking was shorter $(\mathrm{p}<0.001)$ in e-smokers ( $2.5 \pm 2.1$ years) compared to tobacco smokers ( $3.8 \pm 2.1$ years). Among exclusive

Table 1. Frequency of tobacco smoking and e-smoking among students of medicine (Medical University of Silesia in Katowice, Poland)

\begin{tabular}{|c|c|c|c|c|}
\hline Type of smoker & $\begin{array}{c}\text { Total } \\
\mathbf{n}=1318 \\
\% \\
(95 \% \mathrm{CI})^{*}\end{array}$ & $\begin{array}{c}\text { Women } \\
\text { n= 865 } \\
\% \\
(95 \% \text { CI) }\end{array}$ & $\begin{array}{c}\text { Men } \\
n=453 \\
\% \\
(95 \% \mathrm{Cl})\end{array}$ & $\mathbf{p}^{* *}$ \\
\hline Tobacco cigarette & $\begin{array}{c}18.13 \\
(16.15-20.31)\end{array}$ & $\begin{array}{c}16.42 \\
(14.10-19.03)\end{array}$ & $\begin{array}{c}21.41 \\
(17.88-25.42)\end{array}$ & 0.02 \\
\hline E-cigarette & $\begin{array}{c}1.29 \\
(0.81-2.06)\end{array}$ & $\begin{array}{c}1.04 \\
(0.55-1.97)\end{array}$ & $\begin{array}{c}1.77 \\
(0.90-3.45)\end{array}$ & \\
\hline Dual smoker & $\begin{array}{c}2.2 \\
(1.54-3.14)\end{array}$ & $\begin{array}{c}1.73 \\
(1.05-2.84)\end{array}$ & $\begin{array}{c}3.09 \\
(1.85-5.12)\end{array}$ & \\
\hline Non-smoker & $\begin{array}{c}78.38 \\
(76.07-80.51)\end{array}$ & $\begin{array}{c}80.81 \\
(78.05-83.30)\end{array}$ & $\begin{array}{c}73.73 \\
(69.49-77.57)\end{array}$ & \\
\hline
\end{tabular}

95\% confidence interval; ${ }^{* *}$ results of Chi-square test 
Table 2. Pattern of cigarette and e-cigarette use in dual smokers, among students of medicine (Medical University of Silesia in Katowice, Poland)

\begin{tabular}{|c|c|c|c|}
\hline \multicolumn{3}{|c|}{ Dual users $n=29$} & \multirow{2}{*}{$\mathbf{p}^{* *}$} \\
\hline & $\begin{array}{c}\text { Traditional } \\
\text { n; \% (95\% CI) }\end{array}$ & $\begin{array}{c}\text { E-cigarette } \\
\text { n; \% (95\% Cl) }\end{array}$ & \\
\hline \multicolumn{4}{|l|}{ Duration of smoking } \\
\hline Less than 6 months & $\mathrm{n}=2 ; 6.9(1.9-22.0)$ & $\mathrm{n}=8 ; 27.6(14.7-45.7)$ & \multirow[t]{4}{*}{$p=0.001$} \\
\hline $6-12$ months & $\mathrm{n}=3 ; 10.3(3.6-26.4)$ & $\mathrm{n}=9 ; 31.0(17.3-49.2)$ & \\
\hline $1-5$ years & $\mathrm{n}=15 ; 51.7(34.4-68.6)$ & $\mathrm{n}=12 ; 41.4(25.5-59.3)$ & \\
\hline Over 5 years & $\mathrm{n}=9 ; 31.0(17.3-49.2)$ & $\mathrm{n}=0 ; 0(0.00-11.7)$ & \\
\hline \multicolumn{4}{|l|}{ Frequency of use } \\
\hline Daily & $\mathrm{n}=20 ; 69.0(50.8-82.7)$ & $\mathrm{n}=16 ; 55.2(37.5-71.6)$ & \multirow{4}{*}{$p=0.01$} \\
\hline 2-3 times a week & $\mathrm{n}=3 ; 10.3(3.6-26.4)$ & $\mathrm{n}=4 ; 13.8(5.5-30.6)$ & \\
\hline Once a week & $\mathrm{n}=3 ; 10.3(3.6-26.4)$ & $\mathrm{n}=2 ; 6.9(1.9-22.0)$ & \\
\hline Less than once a week & $\mathrm{n}=3 ; 10.3(3.6-26.4)$ & $\mathrm{n}=7 ; 24.1(12.2-42.1)$ & \\
\hline \multicolumn{4}{|l|}{ Cigarettes per day } \\
\hline $1-5$ & $\mathrm{n}=18 ; 62.1(44.0-77.3)$ & $\mathrm{n}=13 ; 44.8(28.4-62.5)$ & \multirow[t]{4}{*}{$p=0.003$} \\
\hline $6-10$ & $\mathrm{n}=7 ; 24.1(12.2-42.1)$ & $\mathrm{n}=5 ; 17.2(7.6-34.5)$ & \\
\hline $11-20$ & $\mathrm{n}=4 ; 13.8(5.5-30.6)$ & $\mathrm{n}=3 ; 10.3(3.5-26.4)$ & \\
\hline Over 20 & $\mathrm{n}=0 ; 0(0.00-11.7)$ & $\mathrm{n}=7 ; 24.1(12.2-42.1)$ & \\
\hline
\end{tabular}

"95\% confidence interval; " results of Chi-square test

e-smokers $(n=17)$ the duration of e-smoking was less than 6 months for 3 of subjects while 4 smoked between 6 and 12 months, 9 persons smoked between 1 and 5 years, and only 1 smoked for over 5 years. Among tobacco smokers $(\mathrm{n}=239)$ the respective numbers of smokers were 11, 24, 152 and 51 persons.

The intensity of e-smoking was larger than the intensity of tobacco smoking $(p=0.01)$. Daily use of cigarettes was declared by 15 e-smokers compared to 114 of tobacco smokers; smoking 2-3 times a week was declared by 1 e-smoker and 63 of tobacco smokers; and smoking only once a week by none of e-smokers and 17 of tobacco smokers. Smoking less than once a week was declared by 1 of e-smoker comparing to 45 of tobacco smokers.

The number of cigarettes smoked per day was significantly higher $(\mathrm{p}<0.001)$ among e-smokers $(17.7 \pm 8.7$ cigarettes/day) compared to tobacco smokers ( $5.8 \pm 5.3$ cigarettes/day). Up to 5 cigarettes per day was smoked by 172 of tobacco smokers and 2 of e-smokers; smoking 6-10 cigarettes per day was declared by 40 tobacco smokers and 2 of e-smokers; smoking 11-20 cigarettes was declared by 20 of tobacco smokers and 7 of e-smokers; smoking over 20 cigarettes per day declared by 4 of tobacco smokers and 6 of e-smokers. Compared to traditional cigarettes, the use of e-cigarettes was associated with a larger intensity of the habit, in terms of daily smoking ( $\mathrm{OR}=8.1,95 \% \mathrm{CI}$ : 1.8-35.9) and smoking more than 20 cigarettes per day $\mathrm{OR}=31.6$ (95\%CI: 7.8-128.6).

Among 29 dual smokers, the duration of e-smoking (1.63 \pm 1.6 years) was significantly $(\mathrm{p}<0.001)$ shorter compared with tobacco smoking (4.42 \pm 2.35 years), as shown in Table 2. Dual smokers more frequently used tobacco cigarettes than e-cigarettes $(p=0.01)$ but they smoked more e-cigarettes per day $(10.7 \pm 9.3$ vs. $6.6 \pm 4.7$ cigarettes; $p=0.003)$.

The respondents reported that the most common places to buy e-liquid are mall stands (41.3\%), tobacco stores (23.9\%) and popular shop networks (17.4\%). The choice of a specific e-liquid depended on the flavour (50.0\%), nicotine concentration (21.7\%) and price (7.6\%). With regard to nicotine content (categories: $0 \mathrm{mg} / \mathrm{mL}$, less than $8 \mathrm{mg} / \mathrm{mL}, 8-16 \mathrm{mg} / \mathrm{mL}$ and over $16 \mathrm{mg} /$ $\mathrm{mL}$ ) e-smokers used e-liquid with a nicotine concentration between 8 and $16 \mathrm{mg} / \mathrm{mL}$ most frequently $(47.8 \%)$. Almost one-third (30.4\%) used e-liquid with nicotine content less than $8 \mathrm{mg} / \mathrm{mL}$. High-nicotine e-cigarettes (over $16 \mathrm{mg} /$ $\mathrm{mL}$ ) were used by $4.3 \%$ of respondents. Only $6.5 \%$ of e-smokers used e-liquid without nicotine and 


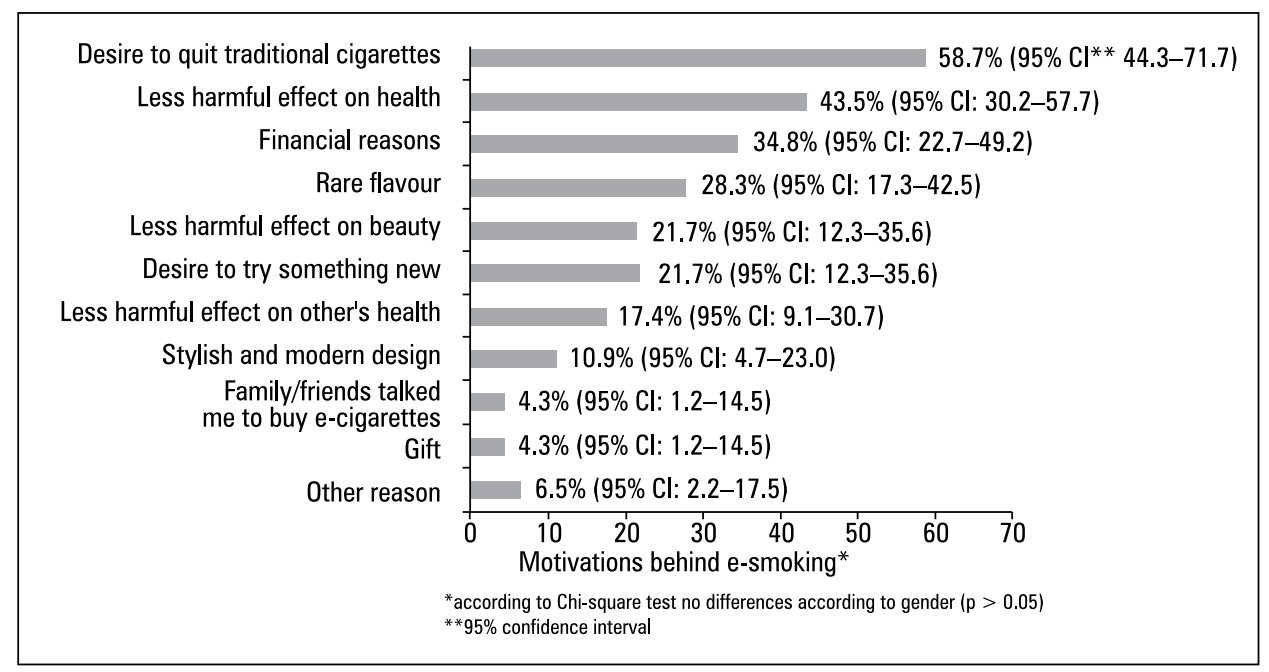

Figure 1. Motivations behind e-smoking among students of medicine (Medical University of Silesia in Katowice, Poland)

$10.9 \%$ did not pay attention to the content of nicotine in the e-liquid. Sub-analysis comparing exclusive e-smokers and dual smokers showed that dual smokers more frequently chose e-liquids with higher nicotine concentration $(\mathrm{p}=0.01)$.

\section{Motivation behind e-smoking}

An attempt to quit tobacco smoking was the most frequently reported factor leading to e-smoking (58.7\%), followed by the perceived less harmful impact on health (43.5\%), and the price (34.8\%). All reasons analysed in the study are shown in Figure 1. Only 11.3\% of e-smokers indicated that they would recommend the use of e-cigarettes to others, while almost half of esmokers (48.7\%) would not recommend the use of e-cigarettes to others.

\section{Opinion about e-smoking in public places}

Only $6.0 \%$ of subjects believed that e-smoking is safe for health and that opinion was shared by $35.5 \%$ of e-smokers and $4.9 \%$ of subjects who do not use e-cigarette $(p<0.001)$. Furthermore, when asked how safe e-cigarettes are, $20.0 \%$ of e-smokers believe that the habit is completely safe for health, and $80.0 \%$ believe that e-smoking is safer than tobacco smoking. Among those, who do not smoke e-cigarettes, the corresponding figures were $9.5 \%$ and $85.7 \%$. Of the respondents, 83.5\% believe e-smoking results in addiction. Of all the respondents, $57.3 \%$ believe that e-smoking should be banned in public places. However, only $16.2 \%$ of e-smokers support e-smoking prohibition in public places, compared with $58.7 \%$ of those who do not smoke e-cigarettes $(\mathrm{p}<0.001)$. All opinions analysed in the study are shown in Table 3.

\section{Discussion}

The results of our study showed that esmoking is not a frequent habit among students at the School of Medicine in Katowice, Poland. Only $3.5 \%$ of responders smoke e-cigarettes and that figure can be compared with $18 \%$ of tobaccosmokers in the study group.

In recent years, e-smoking has gained popularity and is being viewed as an emerging public health challenge. In 2012, the European Eurobarometer publication showed that young people from Central and Eastern Europe were characterized by the relatively high prevalence of e-cigarette usage [2]. According to this expertise, the frequency of any use of e-cigarettes was $34.3 \%$ in Czech Republic, 31.1\% in Bulgaria, $31.3 \%$ in Poland, $31.0 \%$ in Hungary, $22.3 \%$ in Estonia, and $22.2 \%$ in Romania, in comparison to the average level of $20.3 \%$ for the whole European Union. Evidence regarding permanent e-smoking is not widely known. Recent findings showed that in Czech Republic, current e-cigarette use was declared by $9.5 \%$ of responders, and among Polish adolescents, current e-smoking increased from $5.5 \%$ to almost $30 \%$ between 2010 and 2014 [5-7].

Our findings cannot be easily compared with the figures obtained from the general population because of the specific composition of the study group. However, another Polish study showed that $4.4 \%$ of medical students and $12.4 \%$ of non- 
Table 3. Opinions about e-smoking among students of medicine (Medical University of Silesia in Katowice, Poland)

\begin{tabular}{|c|c|c|c|c|}
\hline & $\begin{array}{c}\text { Total } \\
n=1309 \\
\%(95 \% \text { CI) }\end{array}$ & $\begin{array}{c}\text { E-smokers } \\
n=45 \\
\%(95 \% \mathrm{Cl})^{*}\end{array}$ & $\begin{array}{c}\text { Non e-smokers } \\
n=1264 \\
\%(95 \% \mathrm{CI})^{*}\end{array}$ & $\mathbf{p}^{* *}$ \\
\hline \multicolumn{5}{|l|}{ E-cigarettes' safety for health } \\
\hline Yes & $6.0(4.8-7.3)$ & $35.5(23.2-50.1)$ & $4.9(3.8-6.2)$ & 0.000001 \\
\hline No & $77.1(74.8-79.3)$ & $42.2(28.9-56.7)$ & $78.4(76.0-80.5)$ & \\
\hline No opinion & $16.9(14.9-19.0)$ & $22.2(12.5-36.2)$ & $17.5(15.4-19.6)$ & \\
\hline \multicolumn{5}{|c|}{ Possibility to becoming addicted to e-cigarettes } \\
\hline Yes & $83.5(81.4-85.4)$ & $80.0(66.2-89.1)$ & $83.6(81.5-85.6)$ & 0.00008 \\
\hline No & $3.9(3.0-5.1)$ & $15.6(7.7-28.8)$ & $3.5(2.6-4.6)$ & \\
\hline No opinion & $12.6(10.9-14.5)$ & $4.4(1.23-14.8)$ & $12.9(11.1-14.8)$ & \\
\hline \multicolumn{5}{|l|}{ Level of e-cigarette addiction } \\
\hline The same as traditional cigarette & $63.2(60.3-66.0)$ & $30.5(18.0-46.8)$ & $64.3(61.3-67.1)$ & 0.00004 \\
\hline Lower than traditional cigarette & $26.6(24.0-29.3)$ & $58.3(42.2-72.8)$ & $25.5(22.9-28.2)$ & \\
\hline Higher than traditional cigarette & $10.1(8.5-12.1)$ & $11.11(4.4-25.3)$ & $10.1(8.4-12.1)$ & \\
\hline \multicolumn{5}{|l|}{ E-cigarettes' usage in public places } \\
\hline Allowed & $42.6(39.9-45.3)$ & $83.7(70.3-91.8)$ & $41.1(38.2-43.5)$ & 0.00008 \\
\hline Prohibited & $57.3(54.6-60.0)$ & $16.2(8.1-29.9)$ & $58.7(56.0-61.4)$ & \\
\hline
\end{tabular}

${ }^{*} 95 \%$ confidence interval; ${ }^{* *}$ results of Chi-square test

medical students currently use e-cigarettes [8]. In Hungary current e-cigarette usage was declared by less than $1 \%$ of medical students [9].

An interesting observation from our study is that the number of students who simultaneously use both types of cigarettes (dual smokers) is larger than the number of exclusive e-cigarette users, particularly in men. Moreover, dual smokers use a larger number of e-cigarettes compared to tobacco cigarettes and prefer liquids with a higher concentration of nicotine compared to exclusive e-smokers. What is also important is that the majority of e-smokers, even if they believe that e-cigarettes are safer than traditional cigarettes, are convinced about addiction to e-cigarettes.

Available evidence regarding the relationship between e-smoking and tobacco smoking is inconsistent [10-12]. Some findings suggest that e-smoking can be an effective tool to aid smoking cessation, with the overall smoking cessation rate reaching $13 \%[11,12]$. Another study showed that after starting e-smoking, dual users reduced the number of traditional cigarettes by half [13]. In our study, the percentage of daily smoking is much higher among exclusive e-smokers than among conventional smokers. In the case of dual smokers, the frequency of daily tobacco cigarette use is higher than the daily use of e-cigarettes at
$69.1 \%$ and $55.0 \%$, respectively. These results are comparable to the results from studies performed in a group of Polish adolescents, proving that dual users reach for both types of cigarettes more often than single product users $[6,14]$. This could possibly result from a stronger addiction in this group. American data showed that most e-smokers (45.4\%) used e-liquid with a nicotine concentration of less than $8 \mathrm{mg} / \mathrm{ml}$, and only $2.8 \%$ were nicotine-free e-smokers. Our study revealed that high concentration of nicotine use $(8-16 \mathrm{mg} / \mathrm{mL})$ was reported by $47 \%$ of e-smokers whereas only $6.5 \%$ of e-smokers used nicotine free e-liquids. This result confirms another observation from Poland that dual users prefer e-liquid with a higher nicotine concentration [14]. In long-term e-smokers, a decrease in nicotine content can be compensated by an increased amount of e-liquid consumed per day [15]. These findings hamper a view concerning the use of e-smoking as an effective tool in smoking cessation.

The most common reasons to start e-smoking were willingness to reduce or quit tobacco smoking as well as the financial and health reasons. Our findings correspond with other data from Central and Eastern Europe [5-8]. Also, the report by the 2015 Eurobarometer identifies a will to reduce or stop smoking tobacco and the ability to smoke in public places as the two most frequent 
motivations to use e-cigarettes, with $67 \%$ and $44 \%$ respectively [16]. This view could, at least in part, reflect media advertising which suggests that e-cigarettes are a safer alternative to tobacco cigarettes and will help to quit smoking. Our study revealed other factors as well. More than one-fourth of e-smokers (28.3\%) decided to start e-smoking because of the unique flavours of the vapour created by e-cigarettes. Furthermore, for one-half of e-cigarette users, the flavour was the most important factor in choosing an e-liquid. In general, e-smokers believe that e-cigarettes are safer that traditional cigarettes [5, 7, 9]. Moreover, dual smokers admit that dependence on e-cigarettes is lower than dependence on traditional cigarette [13].

Our study targeted a specific group that has better than average health awareness potentially resulting in a healthier lifestyle. For example, the prevalence of tobacco smoking in Poland among young adults is around $24-34 \%$ and among students of medicine it is $14-18 \%[7,8,17]$. A similar direction of this difference is also apparent for e-smoking. This is why the results of our study cannot be generalized to whole population. However our findings add to the epidemiological description of an emerging public health problem. Another limitation of this study is the restriction to medical students in one geographical area, without comparison with other populations of students of medicine or with non-medical students. In this study we also did not ask about the past use of e-cigarettes and focused only on current e-smokers. Nevertheless, our study is characterized by a large sample size of the group and a high response rate.

\section{Conclusions}

Among students of medicine, e-smoking is not a frequent habit and it is apparently less popular than smoking tobacco cigarettes. An analysis of the pattern of e-cigarette use indicates that the percentage of smokers smoking daily is definitely higher among e-smokers as compared to people smoking normal cigarettes. A high percentage of dual users, $10.8 \%$ of the total number of tobacco cigarette smokers, can possibly mean that e-cigarettes are used as an additional source of nicotine and not necessarily they are treated as means to quitting smoking. E-smoking as a new and more and more popular source of nicotine has already become a public health concern and should become a subject to proper health policy measures.

\section{Acknowledgements}

We are grateful to Joshua Lawson, BSc, MSc, $\mathrm{PhD}$ from Department of Medicine and Canadian Center for Health and Safety in Agriculture, University of Saskatchewan (Canada) for improving the use of English in the manuscript and organization of the text.

\section{Conflict of interest}

The authors declare no conflict of interest.

\section{References:}

1. Breland AB, Spindle T, Weaver M, et al. Science and electronic cigarettes: current data, future needs. J Addict Med. 2014; 8(4): 223-233, doi: 10.1097/ADM.0000000000000049, indexed in Pubmed: 25089952.

2. Vardavas CI, Filippidis FT, Agaku IT. Determinants and prevalence of e-cigarette use throughout the European Union: a secondary analysis of 26566 youth and adults from 27 Countries. Tob Control. 2015; 24(5): 442-448, doi: 10.1136/tobaccocontrol-2013-051394, indexed in Pubmed: 24935441.

3. Schraufnagel DE, Blasi F, Drummond MB, et al. Forum of International Respiratory Societies. Electronic cigarettes. A position statement of the forum of international respiratory societies. Am J Respir Crit Care Med. 2014; 190(6): 611-618, doi: 10.1164/rccm.201407-1198PP, indexed in Pubmed: 25006874.

4. World Health Organization (WHO). WHO Framework Convention on Tobacco Control, Electronic nicotine delivery systems report by WHO, FCTC/COP/6/10; 21 July, Moscow, Russia, 2014.

5. Kralikova E, Novak J, West O, et al. Do e-cigarettes have the potential to compete with conventional cigarettes?: a survey of conventional cigarette smokers' experiences with e-cigarettes. Chest. 2013; 144(5): 1609-1614, doi: 10.1378/chest.12-2842, indexed in Pubmed: 23868661.

6. Goniewicz ML, Gawron M, Nadolska J, et al. Rise in electronic cigarette use among adolescents in Poland. J Adolesc Health. 2014; 55(5): 713-715, doi: 10.1016/i.jadohealth.2014.07.015, indexed in Pubmed: 25344033.

7. Goniewicz ML, Zielinska-Danch W. Electronic cigarette use among teenagers and young adults in Poland. Pediatrics. 2012; 130(4): e879-e885, doi: 10.1542/peds.2011-3448, indexed in Pubmed: 22987874 .

8. Zarobkiewicz MK, Wawryk-Gawda E, Woźniakowski MM, et al. Tobacco smokers and electronic cigarettes users among Polish universities students. Rocz Panstw Zakl Hig. 2016; 67(1): 75-80, indexed in Pubmed: 26953585.

9. Pénzes M, Foley KL, Balázs P, et al. Intention to Experiment With E-Cigarettes in a Cross-Sectional Survey of Undergraduate University Students in Hungary. Subst Use Misuse. 2016; 51(9): 1083-1092, doi: 10.3109/10826084.2016.1160116, indexed in Pubmed: 27159776.

10. Malas M, van der Tempel J, Schwartz R, et al. Electronic Cigarettes for Smoking Cessation: A Systematic Review. Nicotine Tob Res. 2016; 18(10): 1926-1936, doi: 10.1093/ntr/ntw119, indexed in Pubmed: 27113014.

11. Bullen C, Howe C, Laugesen M, et al. Electronic cigarettes for smoking cessation: a randomised controlled trial. Lancet. 2013; 382(9905): 1629-1637, doi: 10.1016/S0140-6736(13)61842-5, indexed in Pubmed: 24029165.

12. Caponnetto P, Campagna D, Cibella F, et al. EffiCiency and Safety of an eLectronic cigAreTte (ECLAT) as tobacco cigarettes substitute: a prospective 12-month randomized control design study. PLoS ONE. 2013; 8(6): e66317, doi: 10.1371/ journal.pone.0066317, indexed in Pubmed: 23826093.

13. Etter JF, Eissenberg T. Dependence levels in users of electronic cigarettes, nicotine gums and tobacco cigarettes. Drug Alcohol Depend. 2015; 147: 68-75, doi: 10.1016/i.drugalcdep.2014.12.007, indexed in Pubmed: 25561385. 
14. Goniewicz ML, Leigh NJ, Gawron M, et al. Dual use of electronic and tobacco cigarettes among adolescents: a cross-sectional study in Poland. Int J Public Health. 2016; 61(2): 189-197, doi: 10.1007/s00038-015-0756-x, indexed in Pubmed: 26521213.

15. Etter JF. A longitudinal study of cotinine in long-term daily users of e-cigarettes. Drug Alcohol Depend. 2016; 160 218-221, doi: 10.1016/j.drugalcdep.2016.01.003, indexed in Pubmed: 26804899.
16. European Commission. Eurobarometer 429. Attitudes of Europeans towards tobacco and electronic cigarettes. Available online: http://ec.europa.eu/health/tobacco/docs/2015_infograph_en. pdf (accessed on 29 07. ; 2016.

17. Machōwicz R, Ciechanska J, Zycinska K, et al. Medical students' aptitude toward smoking in Warsaw, Strasbourg and Teheran. Adv Exp Med Biol. 2013; 755: 195-202, doi: 10.1007/978-94-007-4546-9 25, indexed in Pubmed: 22826067. 